\title{
Study of Morphology and Morphometry of Placenta
}

\author{
Ch. Sudhakarbabu', M. Indira² \\ ${ }^{1}$ Associate Professor, Department of Anatomy, Guntur Medical College, Guntur. Andhra Pradesh Dr. NTR UHS Vijayawada, India, ${ }^{2}$ Professor, Department \\ of Biochemistry, Guntur Medical College, Guntur. Andhra Pradesh Dr. NTR UHS Vijayawada, India.
}

\section{Abstract}

Introduction: The placental examination provide significant information related to intrauterine foetal death, Intrauterine Growth Retardation, Malformations, infections and effects of maternal diseases on fetal growth. The magnitude of the clinical problems related to the development and the functions of the placenta is so vast that it worth undertaking morphological aspect of Human placenta A thorough examination of the placenta is neglected often underestimated by the Physician and Gynecologist Pediatrician and pathologist despite its invaluable role in the fetal development. Subjects and Methods: In our present study, 50 freshly delivered placentae have collected The placenta and the umbilical cord were examined to look for any abnormalities in the shape, cord insertion, and vessels in the cord, placenta weight, its circumference, diameter, volume, and thickness at the level of cord insertion were also noted. Baby's weight at birth and age in weeks, maternal history about diabetes and hypertension were also recorded down. IBM SPSS Statistics for Windows version 20.0, USA was used to do statistical analysis of the measurements. Results: In the present study, the placenta weight, volume, diameter, and circumference show a strong correlation with fetal weight. We found the placenta of round and abnormal shapes in $88 \%$ and $12 \%$ of cases, respectively. In $77 \%$ of cases, we got normal cord insertion and in $23 \%$ of cases, abnormal cord insertion. Statistical analysis of all the parameters of the placenta was done. Conclusion: In our study, Placental weight, volume, diameter, and circumference showed a strong correlation with fetal weight. The knowledge of these measurements on the placenta and umbilical cord will be helpful to the pediatrician and obstetrician in clinical practice.

Keywords: Placenta, Fetal weight, measurements, umbilical cord.

Corresponding Author: Dr. M. Indira, Professor, Department of Biochemistry, Guntur Medical College, Guntur. Andhra Pradesh Dr. NTR UHS Vijayawada, India.

Email: dr.sudhakarbabu@gmail.com

Received: June 2020

Accepted: June 2020

\section{Introduction}

The Human Placenta is a discoid, deciduate, chorioallantoic, hemochorial, and villous organ. It is the most exciting organ, its function often holds the key to fetal growth. It is an organ that transfers vital nutrients from mother to embryo and the waste products from embryo to mother. ${ }^{[1]}$ Its weight is approximately $1 / 6$ th of the fetal weight. The Placenta is the principal cause of maternal and perinatal mortality if it is abnormal, and if there is placental insufficiency, it can even lead to fetal growth retardation. ${ }^{[2]}$ After delivery, if the placenta is inspected meticulously, it can provide much insight into the prenatal health of the baby and the mother. ${ }^{[3]}$ Pregnancy complications like hypertension or gestational diabetes are reflected in the placenta in a significant way. So, the present study was undertaken to quantitatively evaluate various dimensions and analysis of the placenta and their relationship and to note the abnormalities in the placenta as well as the umbilical cord and their clinical significance.

\section{Subjects and Methods}

The present study was carried out on 50 full-term freshly delivered placentae were obtained from the department of the Obstetrics and Gynaecology The placenta and umbilical cords were inspected for any abnormality in shape, cord insertion, and vessels in the cord and various measurements of the placentae were done like placental weight, placental circumference, placental diameter, placental volume, placental thickness at the level of cord insertion. The diameter of the umbilical cord was also measured [Figure 1]. Statistical analyses of the measurements were done, and the relationship between birth weight and placental measurement was investigated.

Table 1: Showing the mean and range of all parameters of the placenta

\begin{tabular}{|l|l|l|l|}
\hline Sno & Parameters & Mean & Range \\
\hline 1 & weight of the placenta & $555 \mathrm{~g}$ & $360-750 \mathrm{~g}$ \\
\hline 2 & volume of placenta & $460 \mathrm{ml}$ & $320-600 \mathrm{ml}$ \\
\hline 3 & circumference of placenta & $57.5 \mathrm{~cm}$ & $45-70 \mathrm{~cm}$ \\
\hline 4 & diameter of placenta & $19.5 \mathrm{~cm}$ & $14-25 \mathrm{~cm}$ \\
\hline 5 & Thickness at insertion of cord & $2.35 \mathrm{~cm}$ & $1.5-3.2 \mathrm{~cm}$ \\
\hline
\end{tabular}

\section{Results}




\section{Sudhakarlahlau \& Indira; Marphalagy and Marphametry of Placenta}

average cord diameter was $1.15 \mathrm{~cm}$. The mean and range of all the parameters of the placenta are shown in [Table 1].

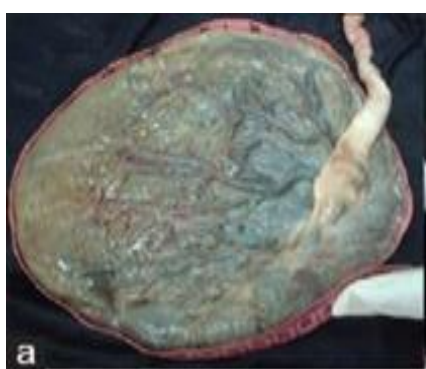

Circumference

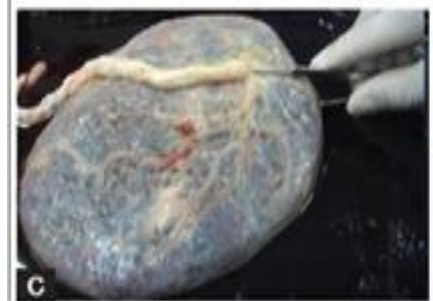

Thickness

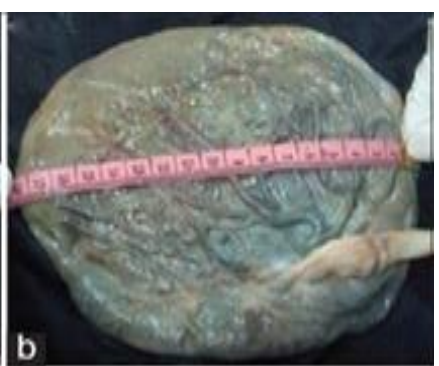

Diameter

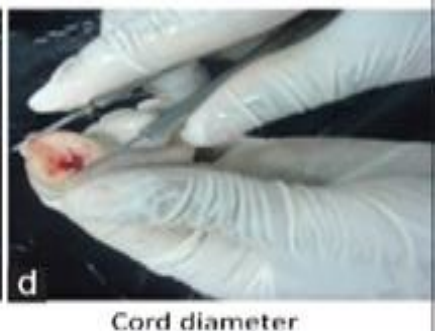

Cord diameter

Figure 1: (a) Circumference of placenta, (b) Diameter of the placenta, (c) Thickness at the level of cord insertion. (d) Diameter of cord

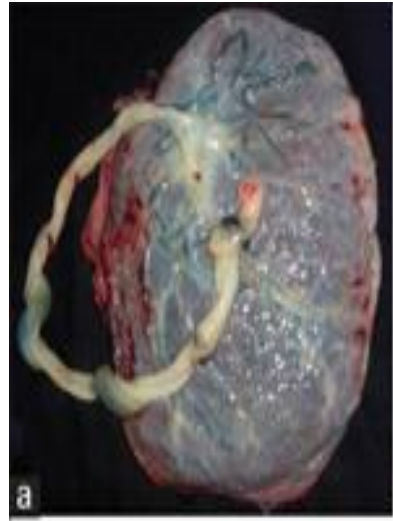

Oval placenta

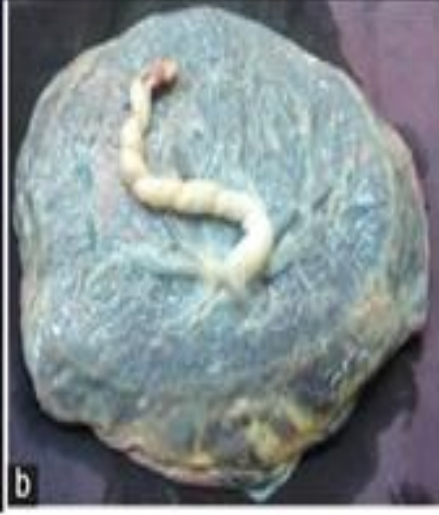

Round placenta

Figure 2: (a) Oval placenta (b) Round placenta

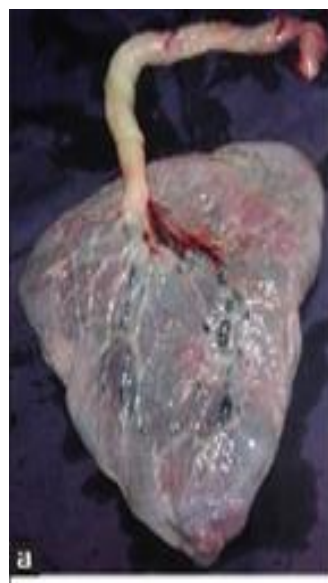

Iriangular Placenta

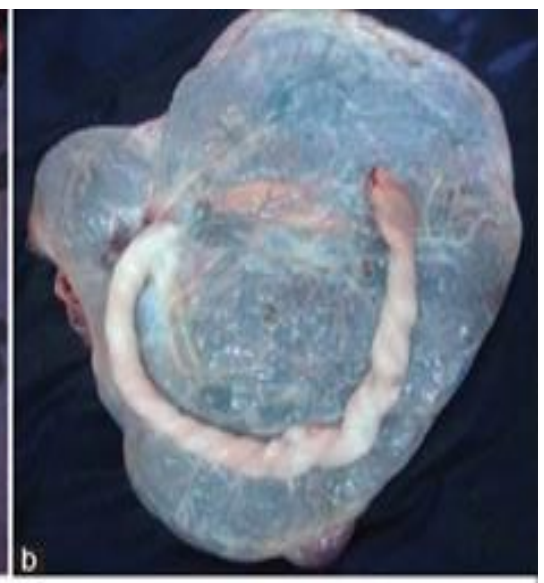

Irregular placente

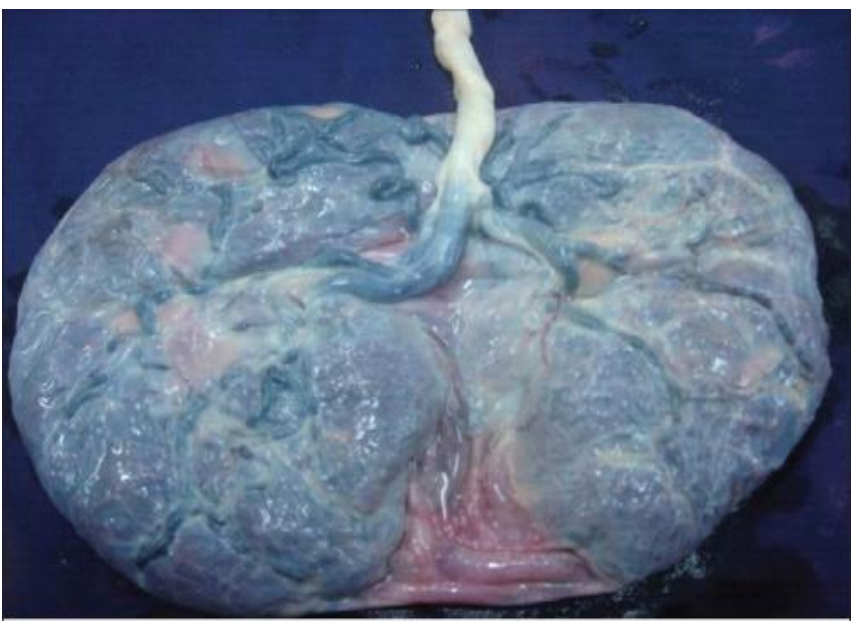

Partial Bilobed Placenta

Figure 4: Partial bilobed placenta

In the present study, we got the oval, round, irregular, triangular, and bilobed shape of the placenta in $6 \%, 90 \%, 1 \%$, $1 \%$, and $2 \%$ of cases, respectively [Figure $2-4]$.

In the present study, placenta weight, volume, diameter, and circumference showed a strong correlation with the fetal weight with a $\mathrm{P}<0.05$, except the thickness of the placenta. We got normal cord insertion in $77 \%$ of cases, marginal insertion in 21\%, and Velamentous insertion of the cord in 2\% [Figure 5].

In all the 50 cases, we got two arteries and one vein in the umbilical cord with no variations.

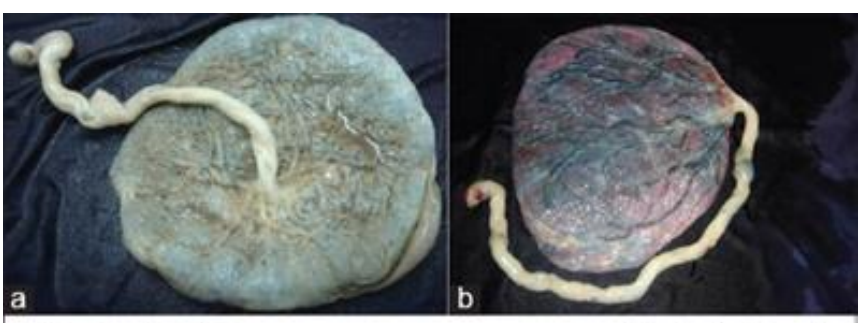

Normal cord insertion

Marginal cord insertion

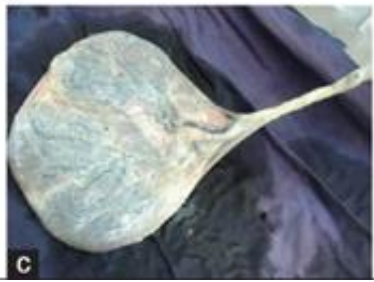

Velamentous cord insertio

Figure 5: (a) Normal insertion of the cord (b) Marginal insertion (c) Velamentous cord

\section{Discussion}

The present study has been taken up to know the normal development of the placenta and associated variations.and made in respect of shape and consistency, attachment of umbilical cord, diameter and thickness, placental weight and volume to provide information and analysis useful for regular clinical practice.

Pathak et al. 2007 found the ratio between fetal birth weight, and placental weight and fetal weight and placental circumference to be 7.2 and 64.57 , respectively. These results 
are similar to our study, and we found the values as 5.6 and 54.22. ${ }^{[7]}$ This ratio is important as in our study we found that the placental weight significantly correlates with the fetal weight. Kovalainen et al. 1997 reported the average diameter of the umbilical cord as $1.5 \mathrm{~cm}$, but in our study, it was 1.15 $\mathrm{cm} .{ }^{[8]}$ According to Yetter (1998), about $7 \%$ of umbilical cord insertions occur at the placental margin but in our study, we found the marginal insertion of cord in $21 \%$ of cases. ${ }^{[4]}$ Londhe and Mane found that in $93 \%$ of the cases, there was a central attachment of cord, while the remaining $7 \%$ had a marginal attachment. ${ }^{[9]}$ Panuganti and Boddeti found that out of 50 placentae, the central attachment was observed in $60 \%$ of the cases, eccentric attachment in $20 \%$, and marginal attachment in $20 \%$ while velamentous attachment was not observed in their study. ${ }^{[10]}$ In our study, central cord insertion was seen in $77 \%$ of cases and marginal insertion in $21 \%$ of cases.

In our study, we also found the velamentous insertion of the cord in $2 \%$ of cases. This velamentous insertion is essential because these cases may lead to an increased risk of fatal hemorrhage. Velamentous cord insertion is also associated with advanced maternal age, diabetes mellitus, smoking, a single umbilical artery, and fetal malformations. ${ }^{[4]}$ Kishwara et al. 2009 found placenta of oval, round, and irregular shape in $38.3 \%, 36.6 \%$, and $25 \%$ of cases, respectively, but in our study, we found that in $6 \%, 90 \%$, and $1 \%$ of cases. ${ }^{[2]}$ Raghunath et al. found that out of the 101 placentae, 94 were circular, and seven were oval. ${ }^{[6]}$ Kulandaivelu et al. found that out of the 51 placentae, 48 were circular and three were oval. ${ }^{[11]}$ Irregular-shaped placentae are mostly seen in premature deliveries that occur due to toxemia. In our study, in $2 \%$ of the cases, we got partial bilobed placenta; these extra placental lobes are important because they may lead to retained placental tissue. Babies born with a disproportionately large placenta are at a higher risk of developing hypertension in their future life. ${ }^{[2]}$ Raghunath et al. and Kulandaivelu et al. found the mean thickness of the placenta to be $2.1 \mathrm{~cm}$ and $1.42 \mathrm{~cm}$, respectively. ${ }^{[6,11]}$ Panuganti and Boddeti found that the thickness of the placenta varied from $1.8 \mathrm{~cm}$ to $3.8 \mathrm{~cm} .{ }^{[10]}$ In our study, the thickness of the placenta was $2.35 \mathrm{~cm}$, which was almost similar to the studies of Raghunath et al. and Panuganti and Boddeti. ${ }^{[4]}$ Panuganti and Boddeti found that the diameter of the placenta varied from $12.2 \mathrm{~cm}$ to $15.8 \mathrm{~cm} .{ }^{[10]}$ Kulandaivelu et al. found the mean diameter of the placenta to be $14.65 \mathrm{~cm} .{ }^{[11]}$ But in our study, the diameter reached $14-25 \mathrm{~cm}$. Panuganti and Boddeti found that the weight of the placenta ranged from 321-534 g, which was almost similar to our research, and we found that the weight ranged $360-750 \mathrm{~g} .{ }^{[10]}$

Table 2: A Comparison of our parameters with the parameters of other authors.

\begin{tabular}{|c|c|c|c|c|}
\hline Studies & Placental weight (g) & Placental diameter $(\mathrm{cm})$ & Placental volume(ml) & Fetal weight $(\mathrm{g})$ \\
\hline Present study & $555 \mathrm{~g}$ & $19.5 \mathrm{~cm}$ & $460 \mathrm{ml}$ & $2954.2 \mathrm{~g}$ \\
\hline Majumdar at all 2005 & $485.8 \mathrm{~g}$ & - ----- & $612.98 \mathrm{~g}$ & $2800 \mathrm{~g}$ \\
\hline Aherne and Dunnell 1966 & $528.55 \mathrm{~g}$ & $17.4 \mathrm{~cm}$ & -------- & $\begin{array}{ll}----- \\
\end{array}$ \\
\hline
\end{tabular}

In our present study, the placental measurements show a strong correlation with fetal weight. The knowledge of these measurements on the placenta and the umbilical cord will be helpful to the pediatricians and obstetricians in regular clinical practice.

\section{Conclusion}

In our study, Placental weight, volume, diameter, and circumference showed a strong correlation with fetal weight. The knowledge of these measurements on the placenta and umbilical cord will be helpful to the pediatrician and obstetrician in clinical practice.

\section{References}

1. Biswas S, Chattopadhyay JC, Ghosh SK. Volume of the placenta and chorionic villi as indicators of intrauterine growth restriction of fetuses. J Anat Soc India 2007;56:25-9.

2. Kishwara S, Ara S, Rayhan KA, Begum M. Morphological changes of the placenta in preeclampsia. Bangladesh J Anat 2009;7:49-54.

3. Majumdar S, Dasgupta H, Bhattacharya K, Bhattacharya A. A study of the placenta in normal and hypertensive pregnancies. J Anat Soc India 2005;54:1-9.

4. Yetter JF 3rd. Examination of the Placenta. Am Fam Physician
1998;57:1045-54.

5. Aherne W, Dunnil MS. Morphometry of the human placenta. $\mathrm{Br}$ Med Bull 1966;22:5-8.

6. Raghunath G, Vijayalakshmi, Shenoy V. A study on the morphology and the morphometry of the human placenta and its clinical relevance in a population in Tamil Nadu. J Clin Diagn Res 2011;5:282-6.

7. Pathak S, Jessop F, Hook L, Sebire NJ, Lees CC. The Placental weight digitally derived placental dimensions at term and their relationship to birth weight. J Matern Fetal Neonatal Med 2010;23:1176-82.

8. Kouvalainen K, Pynnönen AL, Mäkäräinen M, Peltonen T. Weights of the placenta, fetal membranes and umbilical cord. Duodecim 1971;87:1210-4

9. Londhe PS, Mane AB. Morphometric study of placenta and its correlation in normal and hypertensive pregnancies. Int $\mathbf{J}$ Pharma Bio Sci 2011;2:B430-7.

10. Panuganti PK, Boddeti RK. Morphology and morphometric anatomy of placenta. Int J Biol Med Res 2012;3:2165-8.

11. Kulandaivelu AR, Srinivasamurthy BC, Murugan A, Mutharasu A. Morphology and Morphometric Study of Human Placenta in Rural Southern India. Br J Med Med Res 2014;4:295-308. 
Copyright: (C) the author(s), 2020. It is an open-access article distributed under the terms of the Creative Commons Attribution License (CC BY 4.0), which permits authors to retain ownership of the copyright for their content, and allow anyone to download, reuse, reprint, modify, distribute and/or copy the content as long as the original authors and source are cited.

How to cite this article: Sudhakarbabu C, Indira M. Study of Morphology and Morphometry of Placenta. Acad. Anat. Int. 2020;6(1):54-57.

DOI: dx.doi.org/10.21276/aanat.2020.6.1.12

Source of Support: Nil, Conflict of Interest: None declared. 